\title{
Sources of variation of the cattle secondary sex ratio
}

\author{
P Astolfi ${ }^{1}, \mathrm{~S}$ Tentoni ${ }^{2}$ \\ 1 Università di Pavia, Dipartimento di Genetica e Microbiologia 'A Buzzati Traverso', \\ via Abbiategrasso, 207, 27100 Pavia; \\ 2 Istituto di Analisi Numerica del CNR, via Abbiategrasso, 209, 27100 Pavia, Italy
}

(Received 9 March 1994; accepted 24 August 1994)

Summary - The aim of this study was to establish the importance of genetic, biological and environmental factors which may affect sex ratio at birth in dairy cattle. Four main kinds of variations may be considered: heterogeneity between the mothers with respect to the probability of a male birth, variation in this probability according to parity within the progenies; correlation between the sexes of adjacent births, and breeders' decisions. We developed models in which all or some of these factors were simultaneously included, and tested them on a sample of about 266000 dams. The male birth proportion was found to be significantly heterogeneous between dams, increasing over time within progenies, and influenced by the breeder's choice of stopping or continuing the dams' reproductive career. The influence of the sex of a calf on the sex of the following one proved to be non-significant.

secondary sex ratio / non-random variation / Markov dependency / dairy cattle

Résumé - Facteurs de variation du taux de masculinité à la naissance chez les bovins. L'objectif de cette étude est d'évaluer l'importance des facteurs génétiques, biologiques et environnementaux susceptibles d'influencer le taux de masculinité à la naissance chez les bovins laitiers. Quatre sources majeures de variation peuvent être considérées : l'hétérogénéité entre les mères quant à la probabilité de la naissance d'un mâle, la variation de cette probabilité selon la parité, la corrélation entre les sexes des naissances successives et, enfin, les décisions des éleveurs. Nous avons établi des modèles dans lesquels tous ou quelques-uns de ces facteurs sont inclus de façon simultanée et nous les avons éprouvés sur un échantillon d'environ 266000 mères. La proportion des naissances de mâles diffère significativement entre les mères. Elle a tendance à augmenter au fil du temps dans une même descendance et est influencée par le choix de l'éleveur d'arrêter ou de prolonger la carrière reproductive de la mère. Le sexe d'une naissance ne présente pas d'effet statistiquement significatif sur celui de la naissance suivante.

taux de masculinité des naissances / facteur de variation / dépendance markovienne / bovin laitier 


\section{INTRODUCTION}

The common finding that sex ratio at birth (secondary sex ratio) shifts from the expected equal male/female proportion has given rise to investigations about the factors which might influence sex at birth. Possible factors were reviewed in humans by James (1987), and in non-human mammals by Clutton-Brock and Iason (1986). Although the causal mechanisms through which the various factors produce their effects have not been unequivocally confirmed, evidence of resulting non-random variations in male and female births has frequently been found in humans and mammalian natural or domestic populations.

Since the beginning of this century many authors have analyzed sets of data, mostly relative to humans, in order to identify which kinds of variations, in addition to chance, might affect the secondary sex ratio. These analyses, carried out using models which did not provide simultaneous controls for many effects, nevertheless indicated the importance of different kinds of variation (Gini, 1951; Edwards, 1958; Edwards and Fraccaro, 1960; Renkonen et al, 1962; Beilharz, 1963; Edwards, 1966; Greenberg and White, 1967; James, 1975). Genetic, biological and environmental factors may produce different kinds of variation which are generally ascribed to the following 4 classes: (a) variation in the proportion of male and female live births between families; (b) variation in the proportion of male and female live births according to birth orders within families; (c) influence of the sex of one birth on the sex of the following; and (d) variation due to rules in limiting reproduction according to preferences for a certain progeny size or sex composition.

According to (a) and (b), the distribution of progenies is expected to follow 2 extensions of the binomial distribution, the former formalized by Lexis and the latter by Poisson. Edwards (1960) suggested a third generalization by assuming that the sex of one birth might depend on the sex of the previous one (Markov dependency (c)). However, he emphasized the difficulties in identifying these effects, which may confound each other, work in opposite ways and in some cases cancel each other out.

The fourth type of variation (d) is related to choices in limiting procreation aimed at obtaining a more economically profitable male/female ratio. Depending on the population considered, progeny sex ratio can be influenced by birth control, as in man, or by breeders' criteria of selection, as in domestic species.

The purpose of this work was to investigate which kinds of non-random variation, if any, affected the sex ratio of live born calves in a sample of dairy cattle.

In a previous analysis (Astolfi, 1989), evidence of the Lexian sex ratio variation between sibships of the same size was found. However, the underlying model only allowed for this kind of variation; the other effects were not included.

In this analysis we followed a method similar to the one outlined by Pickles $e t$ al (1982); in addition to the variations of points (a), (b) and (d), included in their models, we assumed that the probability of a male birth is conditioned by the sex of the preceding calf (c), according to non-stationary Markovian dependency. The resulting model provides in a simple way simultaneous controls for all the cited effects. 
The relative effect of each source of variation was evaluated by comparing the complete model with simpler models obtained by alternatively excluding some factors.

\section{MATERIALS AND METHODS}

From a large data set provided by AIA (the Italian breeders' association) on the fertility of Italian dairy breeds in the period 1971-1987, a sample of 266518 Friesian dams was selected according to the following criteria. The dams were bred in 4 provinces of Northern Italy and bore at most 10 calves in the period 1975-1984, without any abortions or still births. The total number of calves was 696377 , of which 353167 were males. In this sample, complete information about the calves born was available: the birth date, the number of inseminations preceding the pregnancy and the sex. The sibships were assumed to be completed by 1984 , and all mothers were considered to have stopped reproduction by this year since the available information regarding which dams continued reproductive activity after 1984 was incomplete.

In this work, we considered the sex sequences of length 1,2 and 3 in progenies consisting respectively of the first 1,2 and 3 calves, as well as the sequences of length 4 in progenies of size greater or equal to 4 (see table I for the complete list). In the latter case, attention was focused on the sex of the first 4 calves, pooling longer sequences into the same class.

Table I. Observed frequencies of sex sequences of $1,2,3$ and 4 or more calves.

\begin{tabular}{lclc}
\hline \multicolumn{2}{c}{ Complete progenies of 1, 2 and 3 calves } & \multicolumn{2}{c}{ Progenies with at least 4 calves } \\
Sex sequence $\left(S_{\mathrm{j}}\right)$ & Observed frequency $\left(\mathrm{N}_{\mathrm{j}}\right)$ & Sex sequence $\left(S_{\mathrm{j}}\right)$ & Observed frequency $\left(\mathrm{N}_{\mathrm{j}}\right)$ \\
\hline $\mathrm{m}$ & 45098 & $\mathrm{mmmm}$ & 4320 \\
$\mathrm{f}$ & 42495 & $\mathrm{mmmf}$ & 3938 \\
$\mathrm{~mm}$ & & $\mathrm{mmfm}$ & 4130 \\
$\mathrm{mf}$ & 17664 & $\mathrm{mmff}$ & 3739 \\
$\mathrm{fm}$ & 16257 & $\mathrm{mfmm}$ & 4225 \\
$\mathrm{ff}$ & 17145 & $\mathrm{mfmf}$ & 3909 \\
& 16285 & $\mathrm{mffm}$ & 4083 \\
$\mathrm{mmm}$ & & $\mathrm{mfff}$ & 3821 \\
$\mathrm{mmf}$ & 6057 & $\mathrm{fmmm}$ & 4506 \\
$\mathrm{mfm}$ & 5589 & $\mathrm{fmmf}$ & 4051 \\
$\mathrm{mff}$ & 5681 & $\mathrm{fmfm}$ & 4085 \\
$\mathrm{fmm}$ & 5335 & $\mathrm{fmff}$ & 3995 \\
$\mathrm{fmf}$ & 5984 & $\mathrm{ffmm}$ & 4452 \\
$\mathrm{ffm}$ & 5479 & $\mathrm{ffmf}$ & 4253 \\
$\mathrm{fff}$ & 5701 & $\mathrm{fffm}$ & 4326 \\
& 5447 & $\mathrm{ffff}$ & 4467 \\
\hline
\end{tabular}




\section{Models allowing for more than one factor}

The effects of more than one factor on the probability of a male birth were examined simultaneously, under the hypothesis that different factors may influence the probability of a given sex sequence.

Let us denote by 'sex sequence' $\mathrm{S}$ of length $n$, an ordered $n$-tuple of sexes ( $\mathrm{m}$ and $\mathrm{f}$ standing for male and female respectively), and by $\operatorname{Prob}(\mathrm{S})$ the probability of observing $\mathrm{S}$ in the first $n$ births within the same progeny.

In a model where all dams have the same probability $p$ of bearing a male calf and sexes at birth are considered as independent events, the probability of observing the sex sequence $\mathrm{S}$ is:

$$
\operatorname{Prob}(\mathrm{S})=\prod_{i=1}^{n} p^{s_{i}}(1-p)^{1-s_{i}}
$$

where

$$
s_{i}= \begin{cases}1 & \text { when the } i \text { th birth is a male birth } \\ 0 & \text { when the } i \text { th birth is a female birth }\end{cases}
$$

and $n$ is the length of the sequence.

On the basis of this model, more complicated models were examined allowing for the 4 previously cited sources of variation.

To account for Lexis variation, the probability of the first male birth was considered to vary between dam's progenies. Let us denote by $P_{1}$ the underlying random variable and by $f\left(p_{1}\right)$ its probability density function. For each dam the probability of the $i$ th male birth $p_{i}$, with $i>1$ according to parity, was considered to be a function of $p_{1}$ and of sex of the preceding birth, thus accounting for Poisson variation and non-stationary Markov dependency.

More precisely, the conditional probabilities of the $i$ th male birth $(i>1)$ were expressed as:

$$
\operatorname{Prob}\left[i \text { th male birth } \mid(i-1) \text { th male birth, } P_{1}=p_{1}\right]=k_{i \mathrm{~m}} p_{1}
$$

and

$$
\operatorname{Prob}\left[i \text { th male birth| }(i-1) \text { th female birth, } P_{1}=p_{1}\right]=k_{i \mathrm{f}} p_{1}
$$

with $k_{i \mathrm{~m}}, k_{i \mathrm{f}}$ positive constants, which amounts to assuming that non-stationarity occurs in a similar form across the dams.

Hence, recursively, the probability of the $i$ th birth being male in a progeny where $P_{1}=p_{1}$ is:

$$
p_{i}=\left[k_{i \mathrm{~m}} p_{i-1}+k_{i \mathrm{f}}\left(1-p_{i-1}\right)\right] p_{1}, \quad i>1
$$

As an example, the probabilities of observing the sex sequences $\mathrm{m}, \mathrm{fm}, \mathrm{mfm}$ and mffm are, respectively:

$$
\begin{aligned}
& \operatorname{Prob}\left[\mathrm{m} \mid P_{1}=p_{1}\right]=p_{1} \\
& \operatorname{Prob}\left[\mathrm{fm} \mid P_{1}=p_{1}\right]=\left(1-p_{1}\right) k_{2 \mathrm{f}} p_{1} \\
& \operatorname{Prob}\left[\mathrm{mfm} \mid P_{1}=p_{1}\right]=p_{1}\left(1-k_{2 \mathrm{~m}} p_{1}\right) k_{3 \mathrm{f}} p_{1} \\
& \operatorname{Prob}\left[\mathrm{mffm} \mid P_{1}=p_{1}\right]=p_{1}\left(1-k_{2 \mathrm{~m}} p_{1}\right)\left(1-k_{3 \mathrm{f}} p_{1}\right) k_{4 \mathrm{f}} p_{1}
\end{aligned}
$$


In a more complete model, the possibility of limiting procreation was taken into account and the corresponding 'stopping probabilities' included in the model. The probability $q(\mathrm{~S})$ of stopping a progeny after the occurrence of a particular sequence $\mathrm{S}$ was considered independent of $P_{1}$ but dependent both on progeny size and sex composition.

When the possibility of stopping procreation according to size and sex composition of the progeny is taken into account, the probabilities in [2] become:

$\operatorname{Prob}\left[\mathrm{fm} \mid P_{1}=p_{1}\right]=\left(1-p_{1}\right)(1-q(\mathrm{f})) k_{2 \mathrm{f}} p_{1}$

$\operatorname{Prob}\left[\mathrm{mfm} \mid P_{1}=p_{1}\right]=p_{1}(1-q(\mathrm{~m}))\left(1-k_{2 \mathrm{~m}} p_{1}\right)(1-q(\mathrm{mf})) k_{3 f} p_{1}$

$\operatorname{Prob}\left[\mathrm{mffm} \mid P_{1}=p_{1}\right]=p_{1}(1-q(\mathrm{~m}))\left(1-k_{2 \mathrm{~m}} p_{1}\right)(1-q(\mathrm{mf}))\left(1-k_{3 \mathrm{f}} p_{1}\right)(1-q(\mathrm{mff})) k_{4 \mathrm{f}} p_{1}$

Let us remark that, when evaluating the probability of a sex sequence of length $n$ in a progeny of size equal to $n$, an ending factor $q(\cdot)$ must be considered:

$\operatorname{Prob}\left[\mathrm{fm} \mid \operatorname{prog}\right.$ size $\left.2, P_{1}=p_{1}\right]=\left(1-p_{1}\right)(1-q(f)) k_{2 \mathrm{f}} p_{1} q(\mathrm{fm})$

Prob $\left[\mathrm{mfm} \mid\right.$ prog size $\left.3, P_{1}=p_{1}\right]=p_{1}(1-q(\mathrm{~m}))\left(1-k_{2 \mathrm{~m}} p_{1}\right)(1-q(\mathrm{mf})) k_{3 \mathrm{f}} p_{1} q(\mathrm{mfm})$ Prob $\left[\mathrm{mffm} \mid \operatorname{prog}\right.$ size $\left.4, P_{1}=p_{1}\right]=p_{1}(1-q(\mathrm{~m}))\left(1-k_{2 \mathrm{~m}} p_{1}\right)(1-q(\mathrm{mf}))\left(1-k_{3 \mathrm{f}} p_{1}\right)$ $(1-q(\mathrm{mff})) k_{4 \mathrm{f}} p_{1} q(\mathrm{mffm})$

Let us denote by $\left\{\mathrm{S}_{j}\right\}_{j=1,30}$ all the possible sequences of length equal to or lower than 4 ; the expected proportion of progenies with a particular sex sequence $\mathrm{S}_{j}$ may be found by integration of the sequence probability over $p_{1}$ :

$$
\pi\left(\mathrm{S}_{j}\right)=\int_{0}^{1} \operatorname{Prob}\left[\mathrm{S}_{j} \mid P_{1}=p_{1}, k_{2 \mathrm{~m}}, k_{2 \mathrm{f}}, \ldots k_{4 \mathrm{f}}, q(\mathrm{~m}), q(\mathrm{f}) \ldots q(\mathrm{fff})\right] f\left(p_{1}\right) d p_{1}
$$

From the definition of $r$ th noncentral moment of the $P_{1}$ distribution, $\mu_{r}^{\prime}=$ $\int_{0}^{1} p_{1}^{r} f\left(p_{1}\right) d p_{1}$, it follows that $\pi\left(\mathrm{S}_{j}\right)$ may be expressed as a function of the noncentral moments of the $P_{1}$ distribution.

For example:

$$
\begin{aligned}
\pi(\mathrm{mfm})= & \left(k_{3 \mathrm{f}} \mu_{2}^{\prime}-k_{2 \mathrm{~m}} k_{3 \mathrm{f}} \mu_{3}^{\prime}\right)(1-q(\mathrm{~m}))(1-q(\mathrm{mf})) q(\mathrm{mfm}) \\
\pi(\mathrm{mffm})= & \left(k_{4 \mathrm{f}} \mu_{2}^{\prime}-\left(k_{2 \mathrm{~m}}+k_{3 \mathrm{f}}\right) k_{4 \mathrm{f}} \mu_{3}^{\prime}+k_{2 \mathrm{~m}} k_{3 \mathrm{f}} k_{4 \mathrm{f}} \mu_{4}^{\prime}\right)(1-q(\mathrm{~m})) \\
& (1-q(\mathrm{mf})) q(\mathrm{mff})
\end{aligned}
$$

More generally, the expected frequencies $\pi\left(\mathrm{S}_{j}\right)$ are the product of 2 terms, each depending on a separate subset of variables:

$$
\pi\left(\mathrm{S}_{j}\right)=M_{j}\left(\mu_{1}^{\prime}, \ldots, \mu_{4}^{\prime}, k_{2 \mathrm{~m}}, \ldots, k_{4 \mathrm{f}}\right) \cdot Q_{j}(q(\mathrm{~m}), \ldots, q(\mathrm{fff}))
$$


Maximum likelihood estimates of the parameters were then obtained by maximization of the function $\ln L$ over all the possible sequences:

$$
\begin{aligned}
\ln L= & \sum_{j=1}^{30} N_{j} \ln \pi\left(\mathrm{S}_{j}\right)=\sum_{j=1}^{30} N_{j} \ln M_{j}\left(\mu_{1}^{\prime}, \ldots, \mu_{4}^{\prime}, k_{2 \mathrm{~m}}, \ldots, k_{4 \mathrm{f}}\right) \\
& +\sum_{j=1}^{30} N_{j} \ln Q_{j}(q(\mathrm{~m}), \ldots, q(\mathrm{fff}))=\mathcal{M}\left(\mu_{1}^{\prime}, \ldots, \mu_{4}^{\prime}, k_{2 \mathrm{~m}}, \ldots, k_{4 \mathrm{f}}\right) \\
& +\mathcal{Q}(q(\mathrm{~m}), \ldots, q(\mathrm{fff}))
\end{aligned}
$$

The maximization of the log-likelihood function may be achieved separately for the 2 sets of variables. Each probability $q(\mathrm{~S})$ was estimated as the frequency of the particular sequence $\mathrm{S}$ followed by no more births, $N(\mathrm{~S})$, over all the possible sequences starting with $\mathrm{S}$ and possibly continuing with further births, $N^{*}(\mathrm{~S})$ :

$$
q(\mathrm{~S})=\frac{N(\mathrm{~S})}{N^{*}(\mathrm{~S})}
$$

Since these are maximum likelihood estimates (Pickles et al, 1982), they were included in the model after the maximization of the first term $\mathcal{M}$, in order to simplify the equations and reduce the computing time. The non-linear optimization of the function $\mathcal{M}\left(\mu_{1}^{\prime}, \ldots, \mu_{4}^{\prime}, k_{2 \mathrm{~m}}, \ldots, k_{4 \mathrm{f}}\right)$ was performed by means of the routine E04UCF of the NAG library, Mark 15. In the estimation procedure, all the variables must be constrained to positive values. Moreover, the moments must satisfy the following Liapounoff inequalities:

$$
0 \leqslant\left(\mu_{b}^{\prime}\right)^{a-c} \leqslant\left(\mu_{c}^{\prime}\right)^{a-b}\left(\mu_{a}^{\prime}\right)^{b-c} \leqslant 1 \quad \text { for all } a \geqslant b \geqslant c \geqslant 0
$$

In order to evaluate the importance of each source of variation, 3 different models with fewer parameters were considered beside the complete model:

Model 1. Poisson and Lexis variations and stopping rules by sex sequence were considered; by assuming $k_{i \mathrm{~m}}=k_{i \mathrm{f}}=k_{i}(i=2,3,4)$, Markov dependency was excluded.

Model 2. Stationary Markov dependency, Lexis distribution and stopping rules by sex sequence were considered; by assuming that $k_{i \mathrm{~m}}=k_{\mathrm{m}}, k_{i \mathrm{f}}=k_{\mathrm{f}}(i=2,3,4)$, Poisson variation was excluded.

Model 3. Poisson variation and stopping rules by sex sequences were considered; by assuming $k_{i \mathrm{~m}}=k_{i \mathrm{f}}=k_{i}$ and $\mu_{i}^{\prime}=0(i=2,3,4)$, Markov dependency and Lexis variation, respectively, were excluded.

The frequency distributions expected under the 4 models were fitted to the observed distribution. Then the goodness of fit of the complete model was assessed by the $G$-test, while the effects of the 3 biological factors were evaluated by the likelihood ratio (LR) test of the simpler Models 1, 2, 3 against the complete one.

To evaluate the breeder's influence in limiting the dams' reproductive activity according to sex sequence, stopping rules by progeny size independently of sex composition were also considered, by assuming $q(\mathrm{~m})=q(\mathrm{f})=q(1), q(\mathrm{~mm})=\ldots=$ 
$q(\mathrm{ff})=q(2), q(\mathrm{mmm})=\ldots=q(\mathrm{fff})=q(3)$. In this case, $\pi\left(\mathrm{S}_{j}\right)$ takes a form similar to $[3]$ :

$$
\pi\left(\mathrm{S}_{j}\right)=M_{j}\left(\mu_{1}^{\prime}, \ldots, \mu_{4}^{\prime}, k_{2 \mathrm{~m}}, \ldots, k_{4 \mathrm{f}}\right) \cdot Q_{j}^{\prime}(q(1), q(2), q(3))
$$

and the log-likelihood function becomes:

$$
\ln L^{\prime}=\mathcal{M}\left(\mu_{1}^{\prime}, \ldots, \mu_{4}^{\prime}, k_{2 \mathrm{~m}}, \ldots, k_{4 \mathrm{f}}\right)+\mathcal{Q}^{\prime}(q(1), q(2), q(3))
$$

An LR test was then performed between the quantity $\mathcal{Q}(q(\mathrm{~m}), \ldots, q(\mathrm{fff}))$ in $[4]$ and the analogous quantity $\mathcal{Q}^{\prime}(q(1), q(2), q(3))$.

\section{RESULTS}

Table I shows the observed frequencies of all the possible sex sequences in progenies ranging from 1 to 3 calves and with 4 or more calves. The probabilities of limiting procreation, allowing for both progeny sex composition and size or for size only, were estimated according to [5] and are shown in table II.

Table II. Estimates of the stopping probabilities according to progeny size and sequence

\begin{tabular}{lccc}
\hline $\begin{array}{l}\text { Sex sequence } \\
\left(S_{\mathrm{j}}\right)\end{array}$ & $\begin{array}{c}\text { Stopping probability according } \\
\text { to sequence and size }\left(\mathrm{q}\left(S_{\mathrm{j}}\right)\right)\end{array}$ & $\begin{array}{c}\text { Progeny size } \\
(\mathrm{n})\end{array}$ & $\begin{array}{c}\text { Stopping probability } \\
\text { according to size }(\mathrm{q}(\mathrm{n}))\end{array}$ \\
\hline $\mathrm{m}$ & 0.3369 & 1 & 0.3287 \\
$\mathrm{f}$ & 0.3203 & $"$ & $"$ \\
$\mathrm{~mm}$ & 0.3888 & 2 & 0.3764 \\
$\mathrm{mf}$ & 0.3754 & $"$ & $"$ \\
$\mathrm{fm}$ & 0.3789 & $"$ & $"$ \\
$\mathrm{ff}$ & 0.3624 & 3 & $"$ \\
$\mathrm{mmm}$ & 0.4231 & $"$ & $"$ \\
$\mathrm{mmf}$ & 0.4153 & $"$ & $"$ \\
$\mathrm{mfm}$ & 0.4112 & $"$ & $"$ \\
$\mathrm{mff}$ & 0.4030 & $"$ & $"$ \\
$\mathrm{fmm}$ & 0.4115 & $"$ & $"$ \\
$\mathrm{fmf}$ & 0.4041 & $"$ & $"$ \\
$\mathrm{ffm}$ & 0.3957 & & $"$ \\
$\mathrm{fff}$ & 0.3825 & & $"$ \\
\hline
\end{tabular}

Physical difficulties in either carrying on pregnancy or during delivery, and udder pathologies, foreseeably increasing as the progeny size increases, and lowering milk yields, are the main causes of the breeder's choice of stopping dams' procreation. Moreover, the greater difficulties in pregnancy and delivery of male offspring, on average heavier than the female ones, increase the probability of limiting reproduction in progenies with prevalence of male calves.

The complete model, which takes into account the 3 biological factors (Markovian dependency, Poisson and Lexis variations) and the breeders' choices in limiting reproduction, fitted the data very well (table III). 
Table III. Estimates of Poisson-Markov parameters and moments of Lexis distribution under the complete model, and test of fitting to the observed frequencies

\begin{tabular}{lllllc}
\hline \multicolumn{5}{c}{ Complete model } \\
\hline$k_{2 \mathrm{~m}}$ & 1.0117 & $\mu_{1}^{\prime}$ & 0.5022 & $q(\mathrm{~m})^{\mathrm{a}}$ & 0.3369 \\
$k_{2 \mathrm{f}}$ & 1.0069 & $\mu_{2}^{\prime}$ & 0.2541 & $q(\mathrm{f})$ & 0.3203 \\
$k_{3 \mathrm{~m}}$ & 1.0206 & $\mu_{3}^{\prime}$ & 0.1291 & $\cdot$ & $\cdot$ \\
$k_{3 \mathrm{f}}$ & 1.0171 & $\mu_{4}^{\prime}$ & 0.0655 & $\cdot$ &. \\
$k_{4 \mathrm{~m}}$ & 1.0280 & & & $q(\mathrm{fff})$ & 0.3825 \\
$k_{4 \mathrm{f}}$ & 1.0230 & & & & \\
\hline
\end{tabular}

df $5, G=7.45,0.10<P<0.20{ }^{\mathrm{a}}$ The values of the stopping probabilities are reported in table II.

In order to evaluate the effect of each biological factor, we performed the LR test between the complete model and Models 1, 2 and 3, which excluded one factor at a time (table IV). The results obtained by the LR test of model 1 show that the influence of non-stationary Markov dependency (as formalized in $[1 \mathrm{a}]-[1 \mathrm{~b}]$ ) is not significant. However, suggestions of a weak effect might follow from the $k_{j \mathrm{~m}}$ values, which are always greater than the corresponding $k_{j \mathrm{f}}$ values, thus revealing that after a male calf the probability of a male birth was slightly higher than the probability of a female birth. On the contrary, the LR tests of Models 2 and 3 show that Poisson variation between birth orders and Lexis distribution of $P_{1}$ between progenies significantly contributed to the sex ratio variation.

The effect of the breeders' selection according to progeny size and sex composition, rather than size only, proved to be relevant by the highly significant LR test of $\mathcal{Q}^{\prime}(q(1), q(2), q(3))$ against $\mathcal{Q}(q(\mathrm{~m}), \ldots, q(\mathrm{fff}))(\mathrm{LR}=217.24,11 d f, P<<0.001)$.

\section{DISCUSSION}

In this paper we simultaneously considered the factors which generally are assumed to influence the secondary sex ratio. This investigation, though limited to the sex sequence of the first 4 births, demonstrated that 3 sources of non-random variation seemed to influence the sex ratio at a significant level: the male proportion, which increases with parity; the probability of the first male calf, which varies between the mothers; and the effect of the breeders' rules in stopping the dams' reproductive life.

The hypothesis that the sex of a born calf may be influenced by the sex of the preceding one was not confirmed at a significant level. Analyses of this factor in different data sets of humans and domestic species showed controversial results. For example, in human populations, Renkonen et al (1962) and Edwards (1966) and, in cattle, Astolfi (1990a,b) found a positive significant correlation between sexes in consecutive births, while Edwards and Fraccaro (1960) and Greenberg and White (1967) did not find any evidence of association. Gray and Hurt (1979), in cattle, 
Table IV. Estimates of Poisson-Markov parameters and moments of Lexis distribution under three simpler models, and likelihood ratio (LR) test against the complete model.

\begin{tabular}{lccc}
\hline & \multicolumn{2}{c}{ Model $^{\mathrm{a}}$} & 3 \\
\hline$k_{2}$ & 1 & 2 & 1.0092 \\
$k_{3}$ & 1.0093 & & 1.0186 \\
$k_{4}$ & 1.0189 & & 1.0250 \\
$k_{m}$ & 1.0256 & 1.0178 & \\
$k_{\mathrm{f}}$ & & 1.0128 & \\
$\mu_{1}^{\prime}$ & & 0.5022 & 0.5022 \\
$\mu_{2}^{\prime}$ & 0.5022 & 0.2541 & \\
$\mu_{3}^{\prime}$ & 0.2544 & 0.1290 & \\
$\mu_{4}^{\prime}$ & 0.1295 & 0.0655 & 0.3369 \\
$q(\mathrm{~m})^{\mathrm{b}}$ & 0.0659 & 0.3369 & 0.3203 \\
$q(\mathrm{f})$ & 0.3369 & 0.3203 & $\cdot$ \\
$\cdot$ & 0.3203 & $\cdot$ & $\cdot$ \\
$\cdot$ & $\cdot$ & $\cdot$ & 0.3825 \\
$q(\mathrm{fff})$ & $\cdot$ & 0.3825 & 6 \\
$d f$ & 0.3825 & 4 & 58.20 \\
LR & 3 & 15.00 & $P<0.001$ \\
\hline & 0.80 & $0.001<P<0.01$ & \\
\hline
\end{tabular}

a Model 1: Markov dependency excluded. Model 2: Poisson variation excluded. Model 3: Markov dependency and Lexis variation excluded. ${ }^{\mathrm{b}}$ The values of the stopping probabilities are reported in table II.

and Gray and Katanbaf (1985), in swine, did not obtain statistically significant results, though correlations between sexes were generally positive. However, in these investigations the other sources of variation had not been explicitly considered, in particular the maternal tendency to generate offspring of one sex, which may be confounded with the positive interaction between sexes in consecutive births. In our analysis, in which Lexian variation between the mothers was considered, the influence of the sex of a birth on the following one, formalized as a non-stationary Markov process, showed a non-significant effect and, when excluded, the reduced Model 1 still fitted the data well. This confirms the results of Pickles et al (1982), which found a good fitting of human data using models not allowing for Markovian association.

The significant effect of parity was confirmed by the LR test of Model 2 against the complete model (table IV). The probability of bearing a male calf seems to increase with parity up to the fourth birth at a rate of about $1 \%$. Evidence of a positive trend in cattle was found by Skjervold and James (1978), while in humans a negative and significant trend was found by Novitski and Sandler (1956), Novitski and Kimball (1958), Pickles et al (1982) and Crouchley and Pickles (1984). 
To explain these opposite trends we must take into account the differences in reproductive activity. In man, births occur during a long interval in the fertile period, while in dairy cattle the breeders' selective choices, aiming at economic profit, make the dam's reproductive activity precocious and short, generally lasting only 4 or 5 years for healthy and highly productive dams. Therefore, it is believable that the reproductive effort starting at a juvenile age, the high milk yield and the inseminations performed soon after parturition are heavily stressing factors. In some mammal populations many authors found evidence that young males are less viable than females and in particular fetal losses are more frequent for male fetuses, especially early in pregnancy (for extensive references, see Trivers and Willard 1973; Clutton-Brock et al 1985). The Trivers-Willard model (1973) assuming that "sex ratio at birth is a measure of tendency to invest in one sex more than the other", predicts that "females in better conditions tend to invest in males"; therefore we could argue that as the maternal conditions improve, the sex ratio increases. With respect to this investigation, we might suggest that, due to her precocious exploitation, the dam gradually reaches complete development and optimal conditions to bear a calf during her fertile period. The consequence might be a decreasing probability of male abortions and an increasing proportion of male births over time. This hypothesis would have to be supported by further analyses of the complete reproductive career of the cow.

A further significant effect concerns heterogeneity between sibships in the probability of the first male birth (table IV, Model 3). Since the sire's contribution generally varies within sibships and hence calves of the same dam are halfsibs, this effect may be considered due to a maternal genetic heterogeneity. Assuming that $P_{1}$ follows a $\beta$-distribution, the 2 shape parameters $(a=89.334, b=88.473)$ were evaluated by a least squares fitting of the first 4 noncentral moments estimated under the complete model. The resulting probability density (fig 1) is nearly symmetric, with most values concentrated around the mean.

From the noncentral moments $\left(\mu_{1}^{\prime}\right.$ and $\left.\mu_{2}^{\prime}\right)$ estimated under the complete model, the variance of the distribution has been evaluated as 0.00190 , close to 0.00265 found by Pickles et al (1982), and in the range $0.0012-0.0032$ evaluated in a previous paper (Astolfi, 1989).

The third very important factor results from the selective criteria. Breeders prefer to stop the reproductive activity of cows that bore more male than female calves, hence causing the sex ratio to lower as the progeny size increases. In fact, for progeny size ranging from 1 to 10 , the male proportion was found to decrease regularly from 0.515 to 0.498 (Astolfi, 1989).

In conclusion, among the factors that, in addition to chance, are generally considered to influence the secondary sex ratio, 3 seem to have significant effects. We hypothesized that 2 of these are associated with breeding conditions aimed at economic profit: the artificial selection that favors dams bearing female calves and directly lowers the sex ratio; and the criteria of herd management that physically stress the youngest mothers and indirectly increase the probability of male fetal losses in the first pregnancies. The third seems to be a genetic factor, which might account for different maternal probabilities in generating male or female offspring, though with a very narrow variability. 


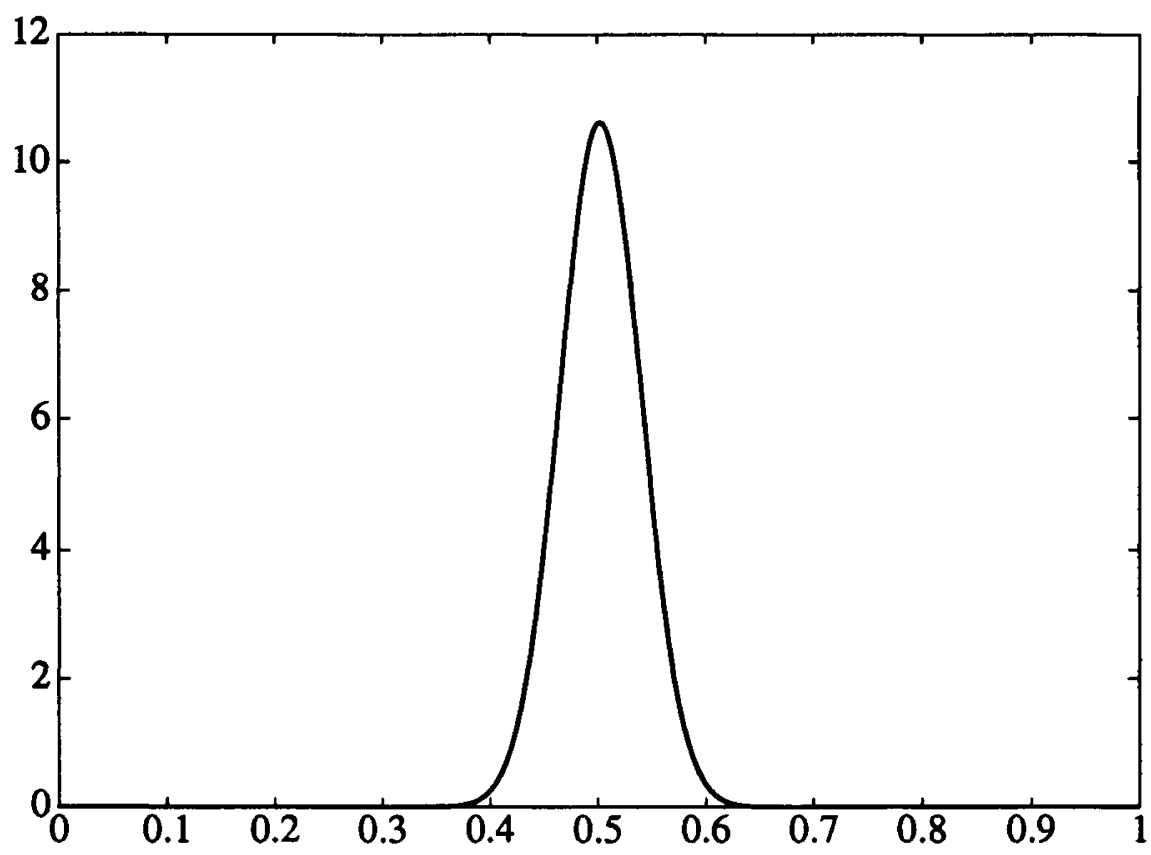

Fig 1. Beta probability density of $P_{1}$, obtained by fitting the noncentral moments $\mu_{i}^{\prime}$ estimated under the complete model.

\section{ACKNOWLEDGMENTS}

We are most grateful to $C$ Matessi for his valuable help in the discussion of the models and to L Zonta for the valid comments on the manuscript. This work was supported by the National Research Council (CNR) 'Gruppo nazionale difesa e valorizzazione del germoplasma animale'.

\section{REFERENCES}

Astolf P (1989) Probability of male births in cattle progenies. J Anim Breed Genet 106, 272-277

Astolfi P (1990a) A correlation between sexes of births in cattle. In: Proc IV World Congr Genetics Applied to Livestock Production. (WG Hill, R Thompson, JA Woolliams, eds), Edinburgh, UK, vol 13, 501-504

Astolf P (1990b) Sex sequences of births pairs in cattle. In: Atti Ass Genet Ital. Perugia, Italy, La Photograph, vol 36, 281-282

Beilharz RG (1963) A factorial analysis of sex-ratio data. A comment on two papers by Edwards. Ann Hum Genet 26, 355-358

Clutton-Brock TH, Iason GR (1986) Sex ratio variation in mammals. Quart Rev Biol 61, No $3,339-374$ 
Clutton-Brock TH, Albon SD, Guinness FE (1985) Parental investment and sex differences in juvenile mortality in birds and mammals. Nature (Lond) 313, 131-133

Crouchley R, Pickles AR (1984) Methods for the identification of Lexian, Poisson and Markovian variations in the secondary sex ratio. Biometrics 40, 165-175

Edwards AWF (1958) An analysis of Geissler's data on the human sex ratio. Ann Hum Genet 24, 6-15

Edwards AWF (1960) The meaning of the binomial distribution. Nature (Lond) 186, 1074

Edwards AWF (1966) Sex ratio data analysed independently of family limitation. Ann Hum Genet 29, 337-347

Edwards AWF, Fraccaro M (1960) Distribution and sequences of sexes in a selected sample of Swedish families. Ann Hum Genet 25, 245-252

Gini C (1951) Combinations and sequences of sexes in human families and mammal litters. Acta Gen Stat Med 2, 220-244

Gray E, Hurt VK (1979) Distribution of sexes in cattle. $J$ Hered 70, 273-274

Gray E, Katanbaf MN (1985) Sex ratio and distribution of sexes in swine. $J$ Hered 76, $36-38$

Greenberg RA, White C (1967) The sexes of consecutive sibs in human sibships. Hum Biol 39, 374-404

James WH (1975) Sex ratio and the sex composition of the existing sibs. Ann Hum Genet $38,371-378$

James WH (1987) The human sex ratio. Part 1: a review of the literature. Hum Biol 59, 721-752

Novitski E, Sandler L (1956) The relationship between parental age, birth order and the secondary sex ratio in humans. Ann Hum Genet 21, 123-131

Novitski E, Kimball AW (1958) Birth order, parental ages, and sex of offspring. Am J Hum Genet 10, 268-275

Numerical Algorithms Group (1991) The NAG Fortran Library Manual, Mark 15. The Numerical Algorithms Group, Oxford, UK

Pickles AR, Crouchley R, Davies RB (1982) New methods for the analysis of sex ratio data independent of the effects of family limitation. Ann Hum Genet 46, 75-81

Renkonen KO, Makela O, Lehtovaara R (1962) Factors affecting the human sex ratio. Nature (Lond) 194, 308-309

Skjervold H, James JW (1978) Causes of variation in the sex ratio in dairy cattle. Z Tierzüchtg Züchtgsbiol 95, 293-305

Trivers R, Willard DE (1973) Natural selection of parental ability to vary the sex ratio of offspring. Science 179, 90-91 